\title{
Colposcopic Evaluation of Visual Inspection with Acetic Acid Positive Cases of Unhealthy Cervix
}

\author{
SB KASEM ${ }^{\mathrm{a}}$, SA RAZZAQUE ${ }^{\mathrm{b}}, \mathrm{RADIBA}^{\mathrm{c}}$, S ANIKA $^{\mathrm{d}}$, M BANIK $^{\mathrm{e}}$
}

\begin{abstract}
Summary:
Cervical cancer is the commonest form of cancer in women in virtually all developing countries ${ }^{1}$. It is the third most common cancer among women worldwide ${ }^{2}$. Almost $80 \%$ of cervical cancer occurs in developing countries. In developed nations, the figure for invasive cervical cancer are much lower due to adaptation of different screening tests ${ }^{1}$. All sexually active women are at risk of acquiring a Human Papilloma Virus (HPV) infection which may lead to cervical cancer in the future ${ }^{3}$. Cervical cancer is a preventable disease as the different screening, diagnostic and therapeutic procedures are effective. The screening procedures are VIA (Visual inspection of cervix with acetic acid), Pap's smear and HPV DNA test. Colposcopy is the triage in screening, taking colpospoy directed biopsy as well as treatment of CIN such as cold coagulation, cryotherapy, and LEEP (Loop electro-surgical excision procedure) 4 .
\end{abstract}

Objective: To study the role of Colposcopy in the evaluation VIA positive cases of unhealthy cervix, to localize the leisons to obtain the biopsies from the selected areas and detection of precancerous lesion of cervix for early management.

Meterials and Methods: This was a prospective observational study done among 306 married women aged 18-65 years who had clinically unhealthy cervix attending the VIA and colposcopy clinic in Department of Obstetrics and Gynaecology of Sir Salimullah Medical College and

Introduction:

A colposcope is a low-power, stereoscopic, binocular field microscope with a powerful light source used for magnified visual examination of the uterine cervix

a. Dr. Setara Binte Kasem, Associate Professor (Gynae \& Obstetrics), Dhaka Medical College, Dhaka.

b. Dr. Shaikh Abdur Razzaque, Professor (Paediatrics Cardiology), National institute of Cardiovascular Diseases, Dhaka.

c. Dr. Raisa Adiba, Honarory Medical Officer, Dhaka Medical College, Dhaka.

d. Selma Anika, Medical Student, Bangladesh Medical College, Dhaka.

e. Dr. Mala Banik, Associate Professor (Gynae \& Obstetrics), Sir Salimullah Medical College and Mitford Hospital, Dhaka.

Address of Correspondence: Dr. Setara Binte Kasem, Associate Professor (Gynae and Obstetrics), Dhaka Medical College, Dhaka. Mob:01552314895, Email: dr.setaraa@gmail.com.

Received: 4 June, 2017

Accepted: 26 December, 2018
Mitford Hospital from January 2015 to December 2016. All the patients were subjected to VIA test. Colposcopic evaluation done in VIA positive cases and the findings were noted. Colposcopy directed biopsy was taken from colposcopically suspected areas.

Results: Out of 306 cases, 63 women had positive VIA tests and 233 women had negative VIA tests. Colposcopic evaluation were undertaken among 63 VIA positive cases. Colposcopy directed punch biopsy revealed that 28 (60.32\%) cases had positive lesions like CIN or invasive carcinoma and 25 (39.68\%) had neither CIN or invasive lesions . Among positive leisons about $30.16 \%$ had CINI, $1.59 \%$ had CIN II, 0\% had CIN III and $28.57 \%$ had invasive carcinoma. In this study sensitivity and specificity of colposcopy examination of VIA positive cases were found $94.74 \%$ and $56 \%$ respectively.

Conclusion: It is evident that colposcopy plays a very important role in the evaluation of VIA positive cases of unhealthy cervix. So that early diagnosis and treatment of preinvasive and early invasive carcinoma of cervixis is possible. So wide use of colposcopy in screening program of Bangladesh specially in the VIA positive cases can reduce the many young women's morbidity and mortality.

(J Bangladesh Coll Phys Surg 2019; 37: 60-65)

DOI: https://doi.org/10.3329/jbcps.v37i2.40561

to help in the diagnosis of preinvasive and early invasive carcinoma of cervix. Modern colposcope usually permits adjustable magnification commonly $6 \mathrm{x}$ to $40 X^{4}$.

Cervical cancer is the fourth most common cancer in the women world wide and is entirely attributable to infection with the Human Papilloma Virus (HPV) ${ }^{2}$. it is the principal cancer of women in most developing countries, where $80 \%$ of cases occur ${ }^{5}$. Every year, 17,686 women in Bangladesh are diagnosed with cervical cancer and 10,364 women die from the disease ${ }^{6}$. Hospital based data revealed that cervical cancer constitutes 22-29\% of female cancer in Bangladesh ${ }^{4}$. There are estimated 450,000 new cases worldwide with about 300,000 deaths each year ${ }^{7}$. Of the new cases detected $86 \%$ occur in developing countries and $14 \%$ in developed countries ${ }^{5}$. In developed nation, the figures 
for invasive cervical cancer are much lower due to adaptation of different screening tests ${ }^{8}$.

Invasive cervical cancers are preceded by a long phase of pre-invasive disease, collectively referred to as Cervical intraepithelial neoplasia (CIN). CIN may be categorized into grades 1,2 and 3 depending upon the proportion of the thickness of the epithelium having mature and undifferentiated cells ${ }^{4}$. The precancerous stage is quite long and ranges from 7 to 20 years which enables early diagnosis and treatment at this stage 4 . Persistent infection with one or more of the oncogenic subtypes of human papilloma virus (HPV) is necessary cause for cervical neoplasia ${ }^{4}$. Studies have shown that HPV is responsible for more than $99.7 \%$ of the cases of invasive cervical cancer worldwide, and it is related to $80 \%$ of precancerous changes in the cervix ${ }^{9}$. The risk factor for high prevalence of cervical cancer in Bangladesh is related to early marriage, early starting of sexual activities, multiparity, STDs, low socioeconomic condition. Therefore, understanding of etiological factors are important for the successful prevention of the disease ${ }^{1}$. VIA of cervix after $3-5 \%$ acetic acid application is a simple and easy to learn method of cervical cancer screening. On exposure to this solution, abnormal cells of the cervical epithelium temporarily turn white and reveal acetowhite epithelium of the abnormal transformation zone ${ }^{10}$.

The term "Unhealthy cervix" encompasses a wide spectrum of conditions. The nacked eye evaluation of the unhealthy cervix is deceptive sometimes and it often happens that intraepithelial precancerous conditions

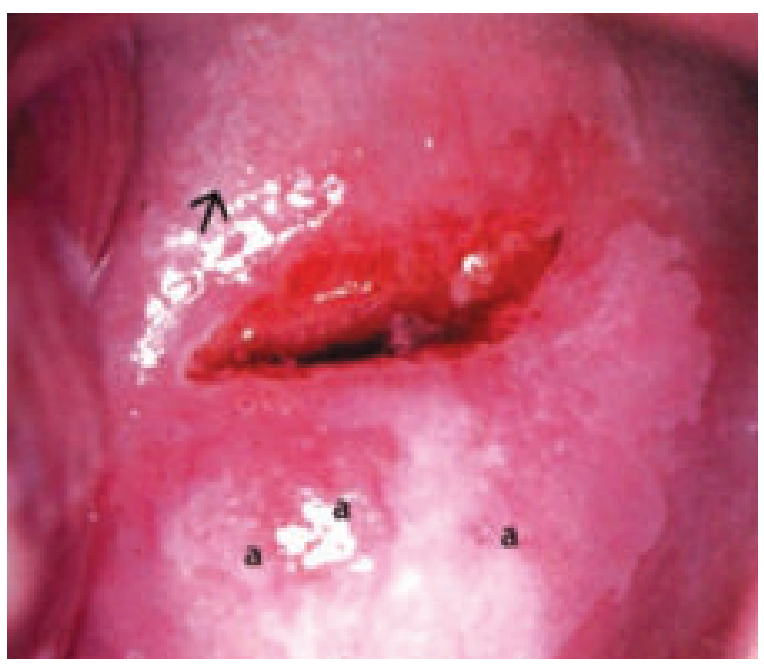

Fig.-1: Colposcopy shows Circumorificial, mild to dense acetowhite lesion with fine mosaic (arrow) are considered as simple cases of erosion due to inflammation ${ }^{11}$.

Rates of cervical cancer are estimated to be at least four fold higher in low resourse countries ${ }^{2}$. The aim of study the role of colposcopy in the evaluation of VIA positive cases of unhealthy cervixis is to localize the leisons and to obtain biopsies from selected areas and detection of precancerous lesion of cervix for early management.

\section{Materials and Methods:}

This was a prospective observational study done among married women who had clinically unhealthy looking cervix attending the VIA and colposcopy clinic of the Department of Obstetrics and Gynecology of Sir Salimullah Medical College and Mitford Hospital from January 2015 to December 2016. A total number of 306 women were included in this study having age range between 18-65 years. All women were counseled. Then informed written consent were taken for VIA, Colposcopy and colposcopy directed biopsy. Among them 63 women had positive VIA test. Colposcopy and Colposcopy directed punch biopsy were taken from the abnormal colposcopic appearance of the VIA positive cases and specimen sent for histopathological examination. Colposcopy was performed in the dorsal lithotomy position with a drape covering the patient's legs. The cervix was visualized using a standard speculum. The colposcopic examination involves the application of three standard solutions to the cervix: Normal saline, 3-5\% acetic acid solution and lugol iodine. Normal saline apply to remove obscuring mucus and debris, to moisture the cervix. Green filter examination of the cervix enhances the angioarchitecture. Acetic acid apply to cervix using soaked swabs. The abnormal colposcopic findings are acetowhite epithelium, abnormal vascular patterns and negative schiller's iodine test.

\section{Result:}

Out of 306 patients 134 (43.79\%) were in the age group of 30-39 years (Table I). $294(96.08 \%)$ patients were house wife. $96(31.37 \%)$ of their husband's occupation were business and 74 (24.18\%) were service holder. $211(68.95 \%)$ of the participants had yearly family income in between 10,000-20,000 (Table II).

Regarding the risk factors $65(21.24 \%)$ patients were married before the age of 15 years and 221 (72.22\%) were married between the age of 15-20 years. Nine (2.94\%) patients had their first child before the age of 15 years and $218(71.24 \%)$ patients had their first child 
between $15-20$ years. $137(44.77 \%)$ of them had 1-2 children and 118 (38.56\%) women had 3-4 children. (Table III).

Colposcopic examination revealed that out of 63 VIA positive patients, 11(17.46\%) had normal colposcopic findings. Colposcopy showed inflammation of cervix in $14(22.22 \%)$ cases, CIN I in $24(38.1 \%)$ cases, CIN II in $10(15.87 \%)$ cases, CIN III in $2(3.17 \%)$ cases and invasive cervical carcinoma in $11(17.46 \%)$ cases (Table V).

Later on histopathology of biopsy (63) showed normal findings in 2(3.17\%) cases, inflammation in 23(36.51\%) cases, CIN I in $19(30.16 \%)$ cases, CIN II in $1(1.59 \%)$ case, CIN III in $0(0 \%)$ case and invasive squamous cell carcinoma in $18(28.57 \%)$ cases (Table VI).

TableI-I

Age distribution of the patients of unhealthy cervix
\begin{tabular}{lcc} 
Age in years $(\mathrm{n}=306)$ & Frequency & Percentage \\
\hline$<20$ & 2 & 0.65 \\
$20-29$ & 62 & 20.26 \\
$30-39$ & 134 & 43.79 \\
$40-49$ & 87 & 28.43 \\
$50-59$ & 13 & 4.25 \\
$60-69$ & 8 & 2.61 \\
\hline
\end{tabular}

Table-II

Distribution of the patients of unhealthy cervix by socio-demographic characteristics

Variables Frequency Percentage

\begin{tabular}{lcc}
\hline Patient's Occupation & & \\
House wife & 294 & 96.08 \\
Service & 12 & 3.92 \\
Husband's Occupation & & \\
Service holder & 74 & 24.18 \\
Business & 96 & 31.37 \\
Day laborer & 38 & 12.42 \\
Driver & 28 & 9.15 \\
Agriculture & 20 & 6.54 \\
Unemployed & 17 & 5.56 \\
Abroad & 18 & 5.88 \\
Died & 15 & 4.9 \\
Yearly Family Income(Taka) & \\
$<10,000$ & 39 & 12.75 \\
10,000-20,000 & 211 & 68.95 \\
$21,000-30,000$ & 30 & 9.8 \\
$31,000-40,000$ & 6 & 1.96 \\
$>41,000$ & 20 & 6.54 \\
\hline
\end{tabular}

\section{Table-III}

\begin{tabular}{lcc}
\multicolumn{2}{c}{ Regarding risk factors of Cervical } & Cancer \\
Variables & Frequency & Percentage \\
\hline Age of marriage & & \\
$<15$ & 65 & 21.24 \\
$15-20$ & 221 & 72.22 \\
$>20$ & 20 & 6.54 \\
Age of first pregnancy & & \\
$<15$ & 9 & 2.94 \\
$15-20$ & 218 & 71.24 \\
$>20$ & 72 & 23.53 \\
Number of parity & & \\
No & 7 & 2.29 \\
$1-2$ & 137 & 44.77 \\
$3-4$ & 118 & 38.56 \\
$>4$ & 44 & 14.38 \\
Number of Abortion & 57 & 18.63 \\
Number of MR & 69 & 22.55 \\
\hline
\end{tabular}

Table-IV

\begin{tabular}{lcc}
\multicolumn{3}{c}{ Screening by VIA } \\
& Total & Percentage \\
\hline VIA positive & 63 & 20.59 \\
VIA negative & 243 & 79.41 \\
\hline
\end{tabular}

Table-V

Distribution of Colposcopic findings of VIA positive cases of unhealthy cervix

\begin{tabular}{lcc} 
Findings & Number $(\mathrm{n}=63)$ & Percent \\
\hline SCJ visualize & 63 & 100 \\
SCJ not visualize & 0 & 0 \\
AW lesion present & 63 & 100 \\
Normal & 11 & 17.46 \\
Inflammation & 14 & 22.22 \\
Colposcopy negative & 25 & 39.68 \\
CIN I & 24 & 38.1 \\
CIN II & 10 & 15.87 \\
CIN III & 2 & 3.17 \\
Invasive Cervical carcinoma & 11 & 17.46 \\
Colposcopy positive & 47 & 74.6 \\
\hline
\end{tabular}


Table-VI

Histopathology results of biopsy specimen of VIA positive cases of unhealthy cervix

\begin{tabular}{lcc} 
Biopsy findings & Number $(\mathrm{n}=63)$ & Percent \\
\hline Normal & 2 & 3.17 \\
Inflammation & 23 & 36.51 \\
Biopsy negative & 25 & 39.68 \\
CIN I & 19 & 30.16 \\
CIN II & 1 & 1.59 \\
CIN III & 0 & 0 \\
Invasive Carcinoma & 18 & 28.57 \\
Biopsy positive & 38 & 60.32 \\
\hline
\end{tabular}

Table-VII

Comparative findings of Colposcopy \& Colposcopy directed biopy of VIA positive cases

ColposcopyFindings of all

Colposcopy directed biopsy findings

VIA positive cases $(n=63) \quad$ Normal Inflammation CIN I CIN II CINIII Invasive

\begin{tabular}{llcc} 
& & carcinoma \\
\hline Colposcopy & 2 & 12 & 2
\end{tabular}

Negative (25)

Normal (11)

Inflammation (14)

Colposcopy

Positive(47)

CIN I (24)

CIN II (10)

\begin{tabular}{|c|c|c|c|c|c|}
\hline \multirow{3}{*}{\multicolumn{2}{|c|}{$\begin{array}{c}10 \\
1\end{array}$}} & 14 & & & \\
\hline & & 5 & \multirow{3}{*}{1} & & 4 \\
\hline & & & & & 1 \\
\hline \multirow{3}{*}{2} & & & & & 11 \\
\hline & 23 & 19 & 1 & $\mathrm{o}$ & 18 \\
\hline & \multicolumn{5}{|c|}{ Total biopsy positive-38 } \\
\hline
\end{tabular}

Table-VIII

Sensitivity and Specificity of Colposcopy in detecting CIN

\begin{tabular}{lccc} 
Colposcopic findings & Disease positive & Negative & Total \\
Positive & 36 & 11 & 47 \\
Negative & 2 & 14 & 16 \\
\hline Total & 38 & 25 & 63 \\
\hline
\end{tabular}

63 
Table-IX

\begin{tabular}{lc}
\multicolumn{2}{c}{$\begin{array}{c}\text { Accuracy of Colposcopy for screening } \\
\text { by statistical analysis }\end{array}$} \\
Colposcopy test accuracy & Result \\
\hline True positive & 36 \\
False positive & 11 \\
True negative & 14 \\
False negative & 2 \\
Senstivity & $94.74 \%$ \\
Specificity & $56 \%$ \\
Positive predictive value & $76.6 \%$ \\
Negative predictive value & $87.5 \%$ \\
\hline
\end{tabular}

Sensitivity and specificity Analysis: The sensitivity and specificity of colposcopy was calculated considering colposcopy directed biopsy as a gold standard ${ }^{1}$. Among the VIA positive cases $74.6 \%$ positive in colposcopy and $60.32 \%$ positive in biopsy. The sensitivity and specificity of colposcopy were $94.72 \%$ and $56 \%$ respectively as shown in table IX.

\section{Discussion:}

Colposcopy, a clinical method of proven accuracy, is an excellent means of evaluating clinically unhealthy cervix ${ }^{8}$. The women in this study varied in age and parity. Out of 306 patients 134 (43.79\%) were in the age group of 30-39 years. World Health Organization suggested the priority age group 35-45 years for the screening of $\mathrm{CIN}^{12}$.

294 (96.08\%) patients were house wife. 96 (31.37\%) patient's husband's occupation were business and 74 $(24.18 \%)$ patient's husband were service holder. Socioeconomic status had always been playing an epidemiological role in genesis of dysplasia ${ }^{13}$. In our study $68.59 \%$ of the respondent's yearly family income were 10,000-20,000. Regarding the risk factors $65(21.24 \%)$ patients were married before the age of 15 years and $221(72.22 \%)$ were married between the age of 15-20 years which corresponds with the study of Rotkin ID $^{14}$. Nine $(2.94 \%)$ women had their first child before the age of 15 years and 218 (71.24\%) patients had their first child between 15-20 years.About $45 \%$ of them had $1-2$ children and 118 (38.56\%) women had 3-4 children. indicating multiparity as a related risk for CIN of the cervix. This observation correlates with the study of Schiffman MH et al and Rotkin $\mathrm{ID}^{15,14}$. Smith believes that poor obstetrical and postpartum care and neglect of the symptoms of a lacerated and ulcerated cervix accounts for the greater frequency of cervical cancer among the poorer classes ${ }^{16}$.

Among VIA positive cases , 25(39.68\%) patients had negative colposcopic findings and $47(74.6 \%)$ patients had positive colposcopic findings, that is $24(38.1 \%)$ had CINI, 10(15.87\%) had CIN II, 2(3.17\%) had CINIII and $11(17.46 \%)$ had invasive carcinoma. Biopsy were done only in VIA positive cases. Biopsy showed normal findings in $2(3.17 \%)$ cases, inflammation in 23(36.51\%) cases, CIN I in $19(30.16 \%)$ cases, CIN II in $1(1.59 \%)$ cases, CIN III in $0(0 \%)$ case and invasive squamous cell carcinoma in $18(28.57 \%)$ cases. Evidence of $\mathrm{CIN}$ and and invasive leisons in colposcopy directed cervical biopsy among the VIA positive patients strongly suggested the need of VIA as an essential screening test.

Within 63 acetowhite positive cases, 47 cases (74.6\%) had positive findings by colposcopy and 38 cases $(60.32 \%)$ had positive findings by biopsy. True positive cases were 36 and true negative cases were 14. False positive were 11 and false negative were 2 . In this study sensitivity and specificity of colposcopy examination were found $94.74 \%$ and $56 \%$ respectively. Many studies have reported sensitivity of colposcopy as $87-99 \%, 96 \%$ and $94.4 \%$ which is comparable to our study ${ }^{17,18,19}$ Specificity of colposcopy in our study was consistent with many studies which reported specificities of $26-87 \%, 57 \%, 50 \%$ and $46.42 \%$ $17,20,21$. There is high sensitivity but low specificity of colposcopy may be due to high incidence of unsuspected acetowhite epithelium which might be due to inflammation, immature metaplasia and latent HPV infection ${ }^{11}$. In our study positive predictive value is $76.6 \%$ and negative predictive value is $87.5 \%$.

The limitation of Colposcopy is its dependence on observer variability and relatively weaker performance in differentiating normal cervix from low grade leisons ${ }^{11}$. The colposcopic diagnosis of CIN requires an understanding and recognition of four main features- colour tone intensity of acetowhitening, margins and surface contour of acetowhite area, vascular pattern and iodine staining. Variations in quality and quantitity of these atypical appearances 
help in differentiating CIN from other lesions and between grades of $\mathrm{CIN}^{22}$.

\section{Conclusion:}

Cervical cancer continues to be a major public health problem that kills approximately a quarter of million women every year and affects developing countries and young women in particular. Colposcopy was found to be useful in understanding the morphology of the cervical lesions, both of the neoplastic and the non neoplastic ones and this was very helpful in planning their management. A detailed colposcopic evaluation of the cervix with a guided biopsy is an important diagnostic method for the detection of preneoplastic and early cervical cancer. So wide use of colposcopy in screening program of Bangladesh can reduce the many young women's morbidity and mortality.

\section{Reference:}

1. Begum K S, Sultana K, Begum R S. Result of Colposcopy among VIA positive cases attending in Colposcopy Clinic of BSMMU. J. Med Sci Jan 2014; 22 (1) :15-22.

2. Jonathan S, Barek, Neville F, Hacker. Berek and Hacker's Gynaecologic Oncology $6^{\text {th }}$ edition, Chapter 7: 242-274.

3. Schiffman M, Susalle K. Natural History of oncogenital human papilloma virus infection and neoplasia. J Natl Cancer Inst 2003: 31:14-19.

4. Banik M, Akhter S N, Kasem S B. Role of colposcopy for the Detection of Precancerous Lesion of Cervix in a Medical College Hospital. ICMH Journal 2016; 7(1):15-19.

5. Waqar F, Begum S, Khatun S et al. Experience with Cervical Diseases: A Hospital Based Study. Bangladesh J Obstel Gynaecol,2004; Vol 19(1):17-21.

6. WHO/ICO Information Centre on HPV and Cervical Cancer (HPV Information centre). Human Papilloma virus and Related Cancers in Bangladesh. Summary Report 2014.

7. Qureshi A, Rather A, Bhagat P. Screening For Cervical carcinoma By VIA. The Internet Journal of Gynecology and Obstetrics.2012 Volume 16(2):1-5.

8. Ramesh G, Sudha R, Jayashree A.K, Padmini J. Colposcopic Evaluation of the Unhealthy Cervix. Journal of Clinical and Diagnostic Research. 2012 August. Vol-6(6): 1026-1028.

9. Wrong LP, Wrong Y L, Low W Y, Khoo E M, Shuib R. Knowledge and awareness of cervical cancer and screening among Malaysian women who have never had a Pap smear: a qualitative study. Singapore Med J 2009; 50(1):49.
10. Ashrafunnesa, Khaleda Nurun Nahar, Shirin Aktar Begum et al Comparison between Visual Inspection of Cervix and Cytology based Screening Procedures in Bangladesh. Asian Pac J Cancer Prev 2013,14(12): 7607-7611.

11. Tapasvi I, Tapasvi C, Aggarwal A and, Aggarwal A. The role of colposcopy, colposcopically directed biopsies and cytology in the evaluation of unhealthy cervix. Indian journal of Basic and Applied Medical Research: June 2015;4(3):150-158.

12. World Health Organization. Human papilloma Virus and cervical cancer( Summary report), Bangladesh. Updated year 2007.

13. Zainab S. Nayani, Pravin Chandra Hendre. Comparision and Correlation of Pap smear with Colposcopy and Histopathology in evaluation of Cervix. J of Evolution of Med and Dent. July 2015; 4 (53): 9236-9247.

14. Rotkin ID. A comparison review of Key epidemiological studies in cervical cancer related to current searches for transmissible agents. Cancer Res 1973;33:1353-67.

15. Schiffman, M,R. Herrero, A.Hildesheim,M.E. Sherman, M. Brattish et al. HPV DNA testing in cervical cancer screening. Results from women in a high-risk province of costa Rica. JAMA .2000 283:87-93

16. Shahriar M, Islam R B, Mahmood A S et al. Risk factors and trends of common cancers in Bangladesh: Outcome of hospital based case control survey conducted in Dhaka city, Bangladesh. S.J. Pharm. Sci.2011 4(2): 35-41.

17. Olaniyan OB. Validity of colposcopy in the diagnosis of early cervical neoplasia- a review. Afr J Reprod Health. 2002 Dec; 6(3):59-69.(

18. Zarchi MK, Binesh F, Kazemi Z, Teimoori S, Soltani HR, Chiti Z. Value of Colposcopy in the Early Diagnosis of Cervical Cancer in patients with Abnormal Pap Smears at Shahid Sadaoughi Hospital, Yazd. Asian Pacific J Cancer Prev. 2011; 12:3439-3441.

19. Adamopoulou M, Kalkani E, Charvalos E, Avgoustidis D, Haidopoulos D, Yapijakis C. Comparison of cytology, colposcopy, HPV typing and biomarker analysis in cervical neoplasia. Anticancer Res. 2009 Aug; 29(8):3401-9. (

20. Zivadinovic R, Radovic M, Lilic V, Petric S. Grading the severity of preinvasive changes of the uterine cervix by colposcopy and exfoliating cytology. 2005; 12(1):55-59.

(21. Ramesh G, Sudha R, Jayashree AK, Padmini J. Colposcopic Evaluation of the Unhealthy Cervix. 2012 August; 6(6):10261028.

22. Jesmin ZF, Khanam A, Saha E, Hossain M. Clinical effectiveness of VIA and colposcopy based management of cervical intraepithelial neoplasia. Bang Med J Khulna 2014; 47:16-20. 